Vietnam Academy of Science and Technology
Vietnam Journal of Earth Sciences
Website: http://www.vjs.ac.vn/index.php/jse

\title{
On new detailed ionogram signatures of Equatorial Plasma Bubbles from non-equatorial station during low solar activity
}

\author{
Nguyen Thu Trang ${ }^{*}$, Roland T. Tsunoda ${ }^{2}$, Le Huy Minh ${ }^{3}$ \\ ${ }^{1}$ Ho Chi Minh City Institute of Physics, Vietnam Academy of Science and Technology \\ ${ }^{2}$ Center for Geospace Studies, SRI International \\ ${ }^{3}$ Institute of Geophysics, Vietnam Academy of Science and Technology
}

Accepted 20 December 2015

\section{ABSTRACT}

A first - time direct comparison between climatology of spread F (SF) observed at Phu Thuy and DMSP, C/NOFS satellite measurements during years of low solar activity conditions 2007 - 2010, together with ionosonde observations under the same solar conditions 1953 - 1955 in Baguio, is made to show good relationship of SF at off-equator and equatorial plasma bubbles (EPB) over the dip equator. The results showed peak of irregularity activities around June solstice, which again confirmed the breakthrough findings by satellites as one typical characteristics of ionospheric structures during low solar activity. We also found that we cannot use typical types of SF for equatorial stations as the ones observed at non-equatorial stations. Instead, we suggested a new method to classify SF types in the relation to ionospheric structures at the off-equator stations of interests. Consequently, we can explain, in the simplest cases, for the first time, complex range type SF observed at off-equatorial stations and name a new type as indicator of EPB occurrence.

Keywords: Spread F, equatorial plasma bubble, ionogram signature.

(C2015 Vietnam Academy of Science and Technology

\section{Introduction}

Equatorial plasma bubbles (EPBs) are referred to as locally depleted irregularity region which their densities are less than those of ambient. The newest working hypothesis, which is most capable for high solar activity period, proposes that once being developed on the crest of an upwelling over the dip equator, EPBs will be launched to higher altitude during mapping in magnetic meridian North-South plane, says even about $3000 \mathrm{~km}$, and move Eastward relative to the upwellings (being

"Corresponding author, Email: trang.nguyen@hcmip.vast.vn controlled by nighttime F-layer dynamo). Besides, secondary EPBs form on the west wall of upwelling and a filling in inside the upwelling region. EPB width is narrow $(<100 \mathrm{~km})$, however it tends to occur in clusters whose zonal widths are similar to those of upwellings and it maps to higher latitudes that EPB may cover a region of about \pm 20 degree in longitude and \pm 20 degree in latitude. The fact that EPB occurrence varies with some factors, such as season, solar activity, longitude, dip latitude... together with its severe effects to ionospheric radio frequency propagation leads to pressing need to better understand this phenomenon towards the probabilities of day-today basis prediction of its variability. Climatology 
N.T. Trang, et al./Vietnam Journal of Earth Sciences 37 (2015)

of EPBs shows quite well-understood behaviors during high solar activity period with two peaks in equinoxes. The observed results from DMSP (Defense Meteorological Satellite Program) and C/NOFS (Communication/Navigation Outage Forecast System) satellites, however, pointed out intriguing features - for the first time - of EPB occurrence during low solar activity period whose maximum is in June solstice and during postmidnight sector with unexpected high percentage. Keeping in mind that satellite measurement is in global scale, though EPB detected by this means is at a fixed altitude and local time over a region of interest. Therefore, continuous observations as function of local time are very important to fill in the gaps of the whole view of EPB characteristics drawn by satellite experiments. To do this, ionosondes at off-equator observatories provide huge source of information about nighttime bottomside $\mathrm{F}$ layer at higher altitudes which are considered to be one of the methods to monitor EPB occurrence and development over the dip equator. And hence, the question is how to interpret the ionogram signatures of EPBs?

Range type spread F (RSF) at low-latitude stations is used by Abdu et al. $(1983,1985)$ in Brazil, Southern Hemisphere, to study the delay of ESF onset at higher latitudes in relative to EPB rise velocity during low to high solar condition period. After that, Whalen et al. (1996, 1997), for the first time, used a chain of some sounders during solar maximum conditions in both North and South Appleton anomaly crests and at dip equator to point out that "RSF at the anomaly always results from bubbles". During years of low solar activity, Sales et al. (1996) show the spread F signatures on ionograms from low-latitude stations in Southern hemisphere totally took the form of range type.

The Phu Thuy ionospheric observatory, locates at $14.37^{\circ}$ dip latitude (calculated from IGRF2010) $\left(21.03^{\circ} \mathrm{N}, 105.96^{\circ} \mathrm{E}\right.$ geographic), has nice datasets of ionograms obtained during all phases of solar activity. Doing statistic of spread F occurrence in more than one solar cycle, Tran Thi Lan and Dao The Cuong showed some characteristics of spread $F$ behavior with both similarities and dissimilarities in compared to other stations in equatorial, low-latitude and anomaly crest regions.
In this paper, following the results in Whalen et al. (1996, 1997), Sales et al. (1996) in which range spread $F$ at anomaly crest stations is considered to be EPB detection, we would like to show in our paper - for the first time - form of spread $F(S F)$ at Phu Thuy in the relation to EPBs to better understand ionogram signatures of the phenomenon and complete their statements about SF regarding the applications of using ionogram as useful detection and monitoring EPBs. We would also like to explain, for some simplest cases, spread F occurrence in Phu Thuy ionograms in light of current hypothesis for EPB development and mapping. Besides, period of low solar activity condition is selected to take advantages from published breakthrough results measured by DMSP, C/NOFS satellites in comparison with SF in ionograms.

\section{Data analysis}

As for low solar conditions, we select four years (2007 - 2010) whose sunspot numbers are $7.5,2.9,3.1$ and 16.5, respectively. We consider geomagnetic quiet conditions denoted by $\mathrm{Kp}<3$. By using Kp index provided on website of World Data Center at Kyoto University, we eliminated nights of $\mathrm{Kp}>3$ in the period of interest. Ionograms were taken every 5 minutes (or 10, 15 minutes during some other times) at Bac Lieu in the collaboration between NICT (National Institute of Information and Communications Technology, Japan) and Institute of Geophysics (Vietnam Academy of Science and Technology, Vietnam). In this paper, we use ionograms provided online on website of SEALION (South East Asia Low latitude IO nospheric Network) project in the courtesy of NICT. The period of time of interest for each night is from 1800 to 0545 local time (LT). SF on reflected F traces is defined as in cases of equatorial ionograms. We however do not classify types of SF based on range or frequency spreading; instead, we are interested in when there is a spreading over $30 \mathrm{~km}$ in altitude and/or 0.3 $\mathrm{MHz}$ in frequency to consider ionograms as SF one. $E$ and $F$ region sunsets are defined as shadow height of the Sun reaches 100 and $250 \mathrm{~km}$ in altitude, respectively, which are calculated from a program for solar zenith angle (program namely "When" written by Dr. Vincent B. Wickwar (SRI International, USA in August 1983). These two sunset times are considered to be around onsets of 
Vietnam Journal of Earth Sciences 37 (2015) 307-317

large-scale wave structure (LSWS) and EPB launch, respectively.

To compare with DMSP and C/NOFS results, we calculate monthly percentage of frequency of occurrence of SF (POFSF) at Phu Thuy by taking all spread $\mathrm{F}$ ionograms in a month divided by total ionograms of the month during period of time as mentioned above, in which we eliminate bad and missing ionograms caused by uncertainties of equipment. We take advantage of published results of EPB occurrence rates in Gentile et al. (2011) paper by extracting from their Figure 3 (a-c) (years 2009, 2008, and 2007, respectively) longitudinal portion of 90 to $120^{\circ}$ East which includes location of Phu Thuy. Similarly, we extract depletion (irregularity) activity in percentage, denoted by normalized depletion of ambient density $(\Delta \mathrm{N} / \mathrm{N})$ from Figure 3a in Dao et al. (2011) paper for period of May 2008 - March 2010. Details of how to obtain these two percentages will be presented in section for results and discussions. We also collect monthly average percentage of SF in Baguio (9.390 dip latitude, 120.50 E geographic longitude) during low solar activity years 19531955 reported in Marasigan (1960) using Figure 2a and redraw in plot for $\mathrm{POF}_{\mathrm{SF}}$ in Phu Thuy.

For case studies, we select two nights, 24 June 2007 and 25 July 2010, with focuses on forms of SF in ionograms in comparison with ones found in Whalen et al. (1996, 1997) and Sales et al. (1996) to find out if range type is only ionogram signature of EPBs. We use also data from other three stations (Bac Lieu, Chiang Mai, Chumphon) to figure out the simplest possible scenario of EBP formation and movement in this area. Locations of these five stations (including Baguio) are shown in Figure 1.

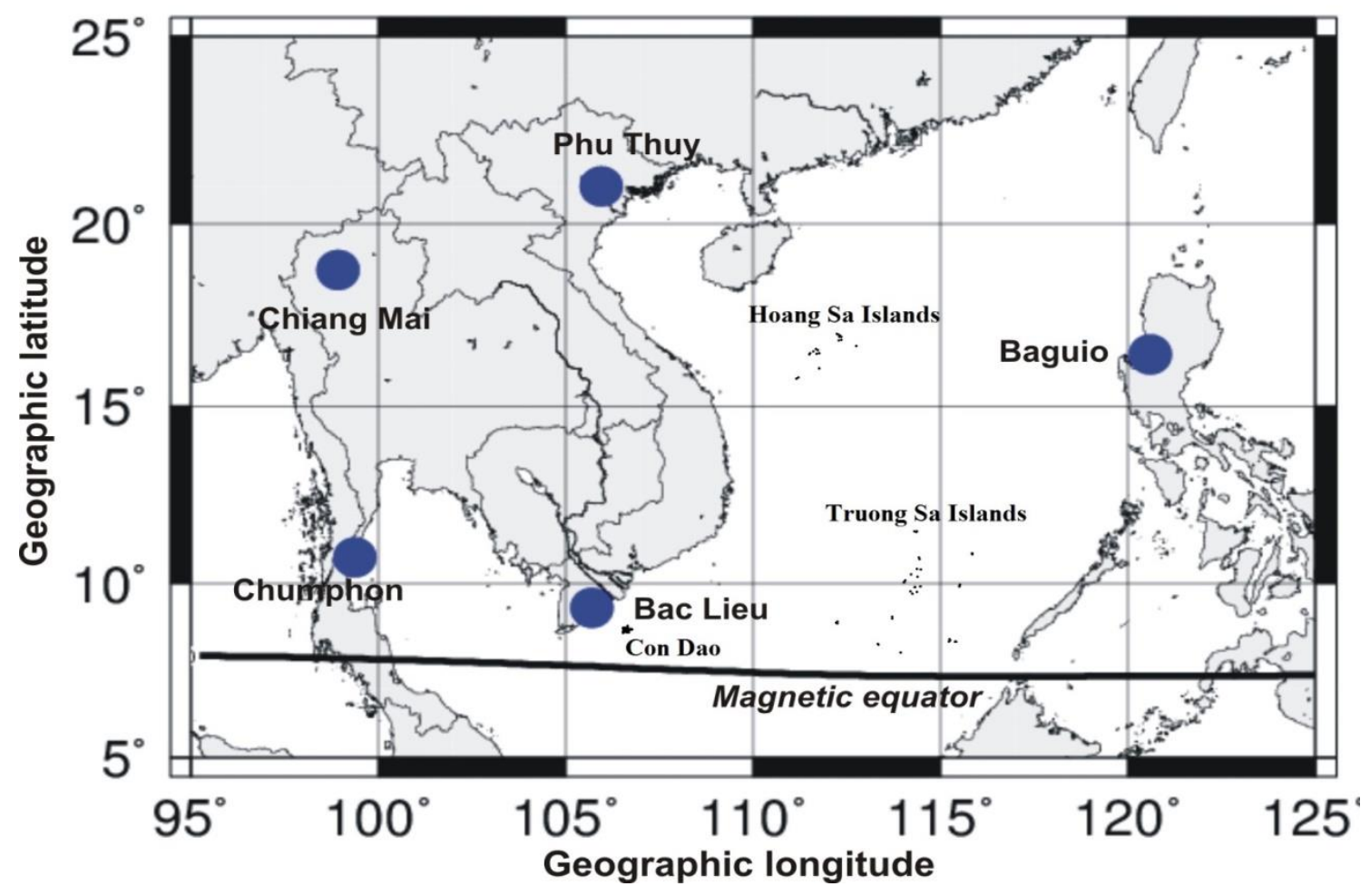

Fig. 1. Locations of five ionosondes in use

\section{Results and discussion}

Starting point of this paper is that EPBs are source of RSF observed at off-equator stations, especially the east and west edges of bubbles, which cause oblique echoes reflected back to the ionosonde, as found in Weber et al. (1978). Keeping in mind that EPBs map along the 
N.T. Trang, et al./Vietnam Journal of Earth Sciences 37 (2015)

magnetic field lines to reach higher dip latitudes, we use equation for geometry of dipole magnetic field to calculate corresponsive altitudes of EPBs that can be seen by ionosondes at other dip latitudes. Assuming that bottomside of nighttime $\mathrm{F}$ layer is about $250 \mathrm{~km}$, we obtain the number as altitude condition for EPBs over dip equator is about $761 \mathrm{~km}$. Above this height, EPBs can reach Phu Thuy.

In Figure 2, we use the Figure $2 \mathrm{~b}$ in Whalen et al (1997) paper and add some notations to show in more detail the simplest way of how EPBs map to higher latitude. The figure represents magnetic meridian plane (North-South plane). Upward black arrow is altitude with scale of $200 \mathrm{~km}$ and intersection point with ground (lowest thick black curve) shows dip equator. At Phu Thuy, red arrow show direction of incident reflected echoes obtained by ionosonde. If we move vertical East West plane at the dip equator along the field lines while keeping this plane perpendicular to the lines to Phu Thuy, then the green arrow points out the direction of this plane at Phu Thuy. In other words, if we look at the ionosphere over Phu Thuy only in the direction of green arrow, we may get reflected signals which are exactly the same with what can be seen right over the dip equator. The dot area shows variation of EPB altitude as a function of dip latitude. As shown there, by two blue lines, EPBs can reach Phu Thuy as long as their altitude is higher than about $760 \mathrm{~km}$ over magnetic equator. Notice that, C/NOFS and DMSP measurements were made at the altitude about $400-850 \mathrm{~km}$ and $840 \mathrm{~km}$, respectively, we have reason to make a comparison of these results to climatology of SF in Phu Thuy to confirm SF's relationship to EPBs; this work is presented in section 3.1. We will come back to Figure 2 for some explanations of form of SF in Phu Thuy, as will be shown in section 3.2, as following.

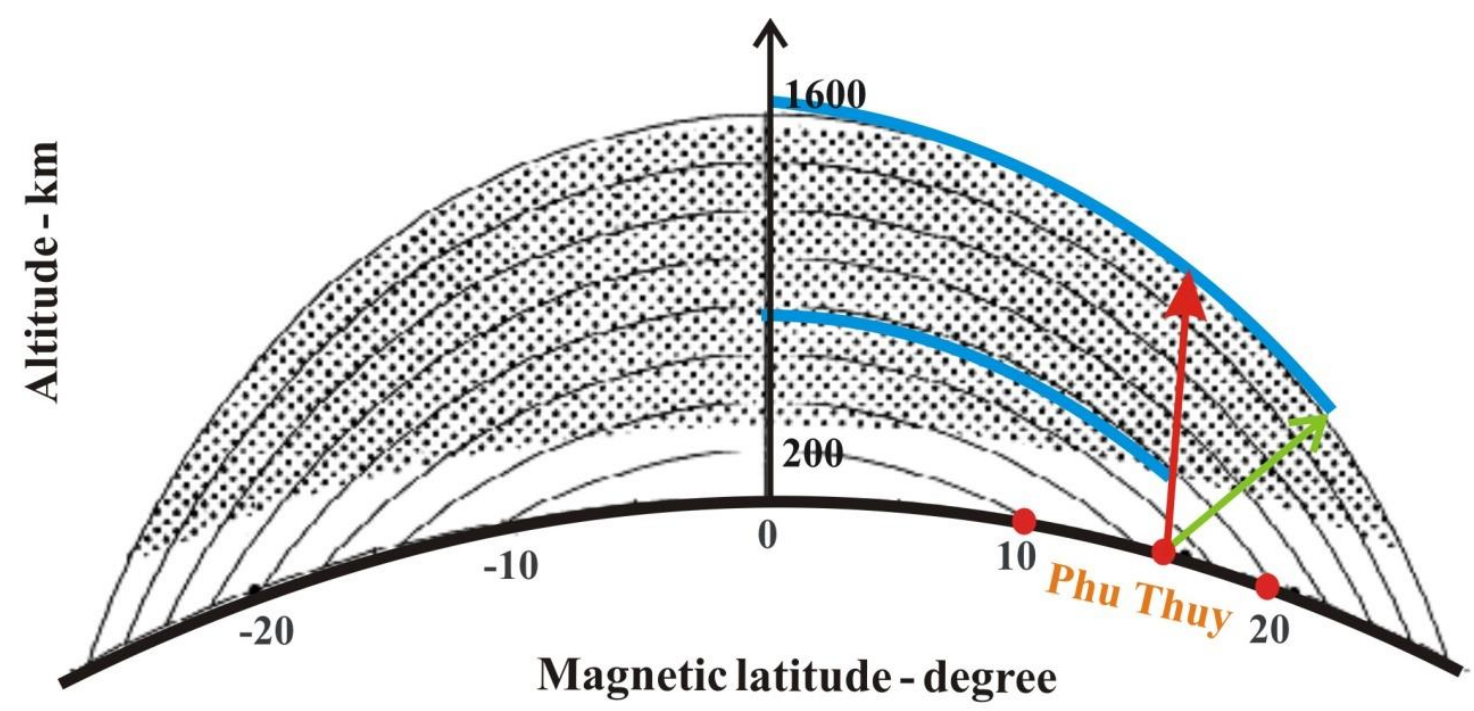

Fig. 2. Model used in Whalen et al., 1997 with added notation showed location of Phu Thuy in the magnetic meridian plane

\subsection{SF at off-equator station Phu Thuy and EPB}

In Figure 3, we combine observations for EPBs from C/NOFS (panels a, b, c), DMSP (panels d, e. f), SF at Phu Thuy in 2007-2010 and at Baguio in 1953-1955 (panel g). All results were obtained in magnetically quiet conditions. In Dao et al., (2011), they used ion density measured by a payload namely Planar Langmuir Probe (PLP). Ambient density (N) was defined as an envelope connecting the local maxima of ion density measurements evaluated every 60 seconds with spline interpolation. Difference between measured density and the envelop in deviation from the ambient density is referred to as $\Delta \mathrm{N}$. The ratio $\Delta \mathrm{N} / \mathrm{N}$ is defined as a measure of plasma 
Vietnam Journal of Earth Sciences 37 (2015) 307-317

irregularity activity. C/NOFS is in equatorial orbit with period is 90 minutes. Data were used in the paper content about ten thousand orbits. Time of interest is between 1800 and 0600 local time (LT). For results extracted in Figure 3, they binned $\Delta \mathrm{N} / \mathrm{N}$ in 1degree latitude by 10 degrees longitude bins. We added red lines to show location of Phu Thuy (around $105^{\circ} \mathrm{E}$ longitude). DMSP F17 spacecraft, in Gentile et al., (2011) paper, flew in Sun-synchronous orbiting with descending node was near the 0530 LT meridian. On average, it completes 14 orbits per day or about 5100 orbits per year. From one orbit to the next one, the descending node advances by about $25^{\circ}$ longitude. Equatorial plasma densities were sampled at evening local times by the Special Sensor-Ions, Electrons, and Scintillation (SSIES) payload. EPB rates were defined as the ratio of the number of orbits with EPBs divided by the total number of orbits for each month of the year within 24 longitude sectors of $15^{\circ}$. For comparison, we only use results in Marasigan (1960) for Baguio, located about $1600 \mathrm{~km}$ East of Phu Thuy since the fact that EPBs drift eastward perhaps $1000 \mathrm{~km}$ or more during several hours of their lifetime. In this scene, EPBs in Vietnam sector could be still active in Philippines region. Using this reason, we are not interested in results obtained in Indian and Central Pacific sectors in the literature in comparing with POFEF in Phu Thuy because their longitudinal difference to Phu Thuy is about 200 apart, West and East of Vietnam, even if their dip latitudes are about similar to that of Phu Thuy. $\mathrm{POF}_{\mathrm{EF}}$ in Baguio was calculated by the same method as used for that in Phu Thuy with ionograms were selected during 1900 to $0800 \mathrm{LT}$.

There are two most noticeable features in Figure 2 that the maximum of both POFSF and bubble occurrence is around June solstice, from May to August, and SF over Phu Thuy seems to occur less than that over Baguio and bubbles observed by satellites. Keeping in mind that SF obtained in Baguio is corresponding to EPBs at about $438 \mathrm{~km}$, we find good agreement between two results for Phu Thuy and Baguio despite the fact that maximum value at Baguio is about more than five times larger than that of Phu Thuy. In this case, potential explanation could be the altitude dependence of EBPs during low solar activity period, when almost EPBs cannot reach higher altitudes compared to that in case of high solar activity period. Consequently, some EPBs seen at $438 \mathrm{~km}$ (observed in Baguio) might not reach 761 $\mathrm{km}$ to be seen by ionograms in Phu Thuy. Although not mentioned in this paper, $\mathrm{POF}_{\mathrm{SF}}$ obtained at Phu Thuy during five years of low solar activity period in 1962-1979 also showed maximum in May-August with peak value is about $14 \%$ and minimum is higher than $0 \%$ (as in our results). Though the authors included magnetic activity nights in their results, which is beyond the scopes of this paper, all these smaller numbers of $\mathrm{POF}_{\mathrm{SF}}$ compared to those at Baguio still show good agreement in light of explanation for EPB altitude. Following this flow of thinking, since C/NOFS was in lower altitude orbit, in average, and sampled during whole night compared to DMSP in slightly higher altitude orbit and took samples once a night solely at $0530 \mathrm{LT}$ in early morning, we found quite higher values in C/NOFS results in comparison to those for DMSP. Besides, we found EBP rate seen by the two satellites, especially for maxima in 2008 and 2009, is quite similar both in months and values of the peaks. We however did not find high peak values of SF over Phu Thuy as for satellites; almost values are about $1 / 3$ compared to EPB rates, except sudden rise in July 2007 although the altitude difference theoretically is not much $(761 \mathrm{~km}$ EPBs to be seen in Phu Thuy). One possible explanation could be the fact that ionosonde cannot see the upper part of the ionosphere, says above the peak of F layer, where bubbles locate. In addition, according to Mendillo and Baumgardner (1982), we might have cases in which Phu Thuy is right in between of two branches of bubble structure where ionograms show normal reflected traces (no SF nights) while bubbles are actually in the vicinity of station.

Since we do not attempt to explain why EPB rates are quite high as shown by satellites, which is still not understood well, some similar characteristics of SF over Phu Thuy in compared with actual measurements by satellites reveals convincingly proofs that SF at non-equatorial stations are caused by EPBs at the dip equator (Whalen 1996 and references therein). To be more convinced, although not shown in this paper by figures, we found that peak of SF occurrence in 
N.T. Trang, et al./Vietnam Journal of Earth Sciences 37 (2015)

Baguio (Phu Thuy) is 0100 LT (0200 LT) and SF was still in ionograms in Baguio even around 1900 LT (early evening) or 0800 LT (well in the morning sector) while there was no $\mathrm{SF}$ in $\mathrm{Phu}$ Thuy before 2000 LT and after 0500 LT. By $\mathrm{C} / \mathrm{NOFS}$, they saw peak of depletion activity is around $0100 \mathrm{LT}-0200 \mathrm{LT}$. These findings lead us to next step of understanding how SF looks like in ionograms as EPB signatures, if it is only range type likes at equatorial stations.

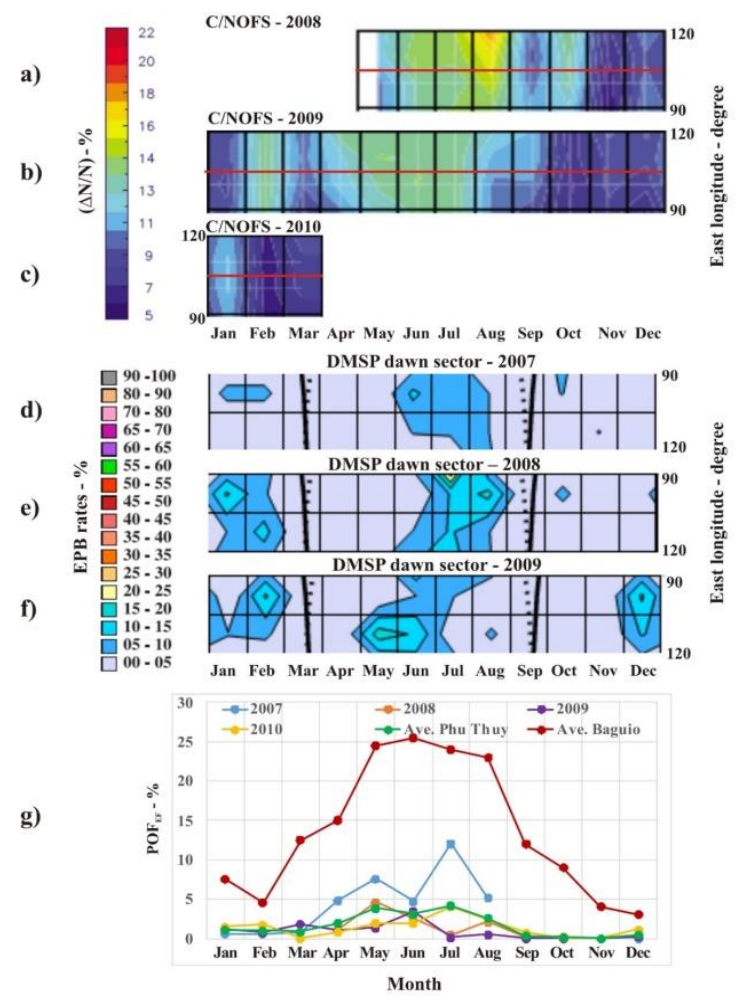

Fig. 1. Composite comparison of EPBs seen by C/NOFS $(a, b, c)$, DMSP $(d, e, f)$ in Vietnam sector, POFSF in Phu Thuy during 2007-2010 and in Baguio during 1953-1955 (g)

\subsection{SF forms in Phu Thuy - a new explanation}

We select two nights of strong SF activity during the period of time of interest, 24 June 2007 and 25 July 2010. In the followings, we are interested in how SFs look like in Phu Thuy ionograms to seek for a potential explanation of their occurrences.

We begin with example of SF sequence observed at southern anomaly crest station - Agua Verde $\left(11^{\circ} \mathrm{S}\right.$ magnetic latitude) - shown by Plate 1 in Sales et al., (1996). This is the only one showing actual ionograms to demonstrate that SF signatures are results from scatter from irregularities within the walls of depleted region. They found indications of SF started around 1909 LT and both range and frequency spread are fully developed 20 min later. These structures lasted for several hours. Very interestingly, since they did not have references for SF types, we found that all SF in their ionograms is equatorial range type mentioned in Chandra and Rastogi (1972) which was used in Whalen et al. (1996, 1997). There is a dissimilarity is that the spreading area in Sales et al., (1996) paper covered a larger scale of frequency - up to more than $14 \mathrm{MHz}$ during its developed phase, instead of horizontal rectangular confined to lower frequencies. Additionally, what they called "indications" is ST from the East and the SF night ended with some spreading region on East ST, again, and from overhead direction around frequencies higher than $F$ layer critical frequency. Notice that measurements were made at southern station, the East direction here is west wall of bubbles and hence, we understand that in this case study ionosonde first saw east wall of bubbles moving eastward from the west. Consequently, SF in ionograms there existed for several hours while bubbles developed from dip equator, moved southward and eastward to Agua Verde and passes to east of the station. We then found that the "edge" which caused STs on this night might be what called "boundaries" of bubbles seen in Whalen et al. $(1996,1997)$ paper, where the authors represented range type SF as results from oblique reflections from depleted regions (bubbles). In Whalen et al. (1996), they used classification of range type as defined by Cohen and Bowles (then used by Chandra and Rastogi, 1972) which is typical equatorial range type while they still noticed of the chaotic nature of range spread F echoes. We found in Weber et al. 1978 that they reported complex range spreading form and created 2-dimentional model to support oblique echoes form west and east edges of depleted region. However, the model is upwelling, according to Tsunoda's hypothesis to explain their results obtained by equipment onboard an airplane. Up to this point, we notice that the authors in the literature used typical equatorial type of SF for 
Vietnam Journal of Earth Sciences 37 (2015) 307-317

non-equatorial SF events while they recognized oblique reflections caused by geometry of bubbles mapped from dip equator. Now, the question is what can be called "range SF" at off-equator stations, Phu Thuy, for example, and if there is other "type" of SF as indications of bubbles?

As we can see in Figure 2, although very simple, what can be seen by ionosonde at Phu Thuy is a combination of reflections from both two directions, the red and green ones. Since EPBs can reach Phu Thuy by both mapping from dip equator and moving from the West, oblique echoes can go back to ionosonde by both titled reflectors in North-South and East-West planes. We can expect, for simplest geometry of EBPs overhead Phu Thuy, that reflections arrive in red arrow direction in East-West plane and both in red and green arrow direction in North-South plane. Consequently, SFs appeared in ionograms are complex caused by mostly oblique echoes from some directions. This may result in shape of range type and what we call "EBP signature "observed in Phu Thuy as represented in Figure 4. We see in there range type traces are the ones where we can find replacement in range not just in vertical direction as in cases of typical one at equator stations, instead it could be tilted as shown in first two images. They are from 24 June 2007 night. Interestingly, we found here one ST at $2345 \mathrm{LT}$ but two STs at 0205 LT. This infers that the ionosphere over Phu Thuy was more structured (complicated geometry) caused by arrivals of EBPs as time passed which supported more oblique reflections. These two events are in good agreement with what suggested by Weber et al., (1996) that there was an undulation or domeshaped structure during earlier bubble phase before evolving into a fully developed depletion. On other night, 25 July 2010, we found a "strange" shape of SF (the right image in Figure 3) showing clear $F$ traces together with some patches around high-end frequencies. We could assume a geometry in which, again using model mentioned in Mendillo and Baumgardner (1982), Phu Thuy was below quite $\mathrm{F}$ layer while bubbles might be to the East or West of station. This is the case of EPB bifurcation. If upward growth velocities of EBP are about 125,150 to $350 \mathrm{~m} / \mathrm{s}$, EPB can reach the altitudes ranged from 375 to $1050 \mathrm{~km}$ after one hour, which is in good agreement to altitudes of bifurcation ranged from around 400 to $750 \mathrm{~km}$ and higher. In other words, EBPs can bifurcate well before they reach Phu Thuy to be seen in the ionograms there as shown in this image. And hence, signals might be able to both be reflected by normal layers and simultaneously go through bubbles and reflected back to the ionosonde to form the patches as seen as spreading area in the ionogram. This kind of ionogram indeed shows appearance of EPBs. Since we cannot name this ionogram as any of three equatorial types, EPB signature might be an appropriate one.

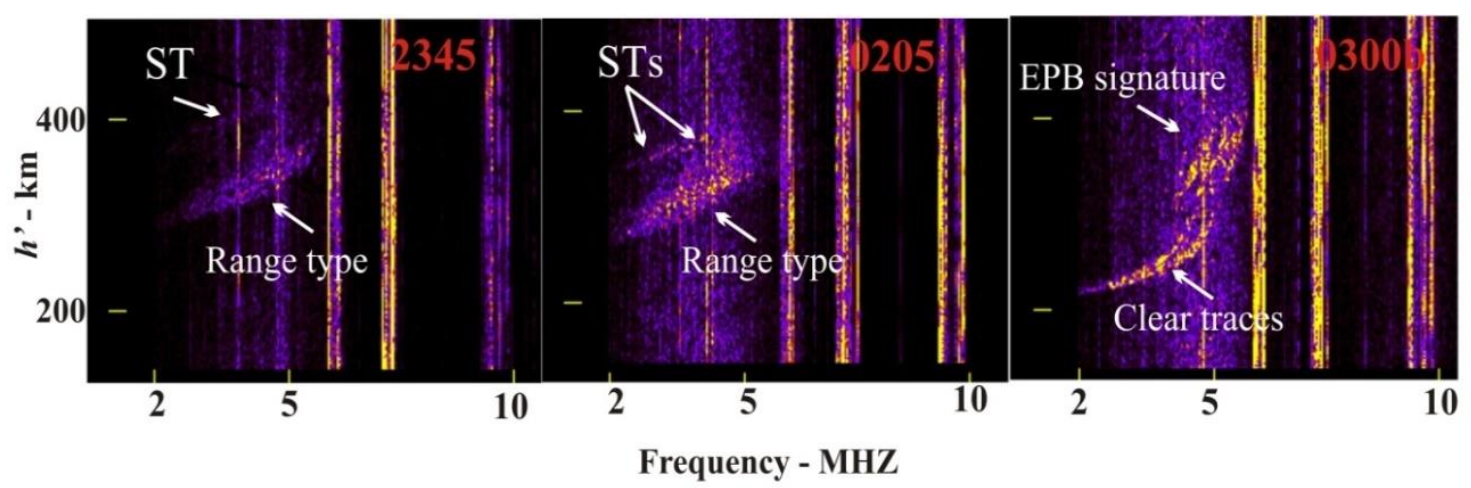

Fig. 4. Some SF forms in Phu Thuy in two case studies

Using our method as mentioned above to classify range type SF, we defined frequency type is when there is replacement in frequency and similarly to mixed type (both range and frequency), we show in Figure 5 all activities of the ionosphere seen by ionograms at Phu Thuy for two selected nights. The behavior of $F$ layer can be seen from plots of virtual heights of reflection, as a function of local time (from $1900 \mathrm{LT}$ to $0545 \mathrm{LT}$ ), for all fixed plasma frequencies extracted from 
N.T. Trang, et al./Vietnam Journal of Earth Sciences 37 (2015)

ionograms. Two vertical black lines, dotted and solid ones, are for $\mathrm{E}$ and $\mathrm{F}$ region sunsets, $\left(S S_{E}\right.$, $S S_{F}$ ) respectively. Short vertical bars are for other activities, as followings: satellite trace (ST) - yellow, range SF - red, mixed SF - purple, frequency SF - blue, other type (EPB signature) - black. Uplifting velocity can be extracted from virtual heights at $3 \mathrm{MHz}$ (bottomside $\mathrm{F}$ layer) in two consecutive 15-min ionograms.

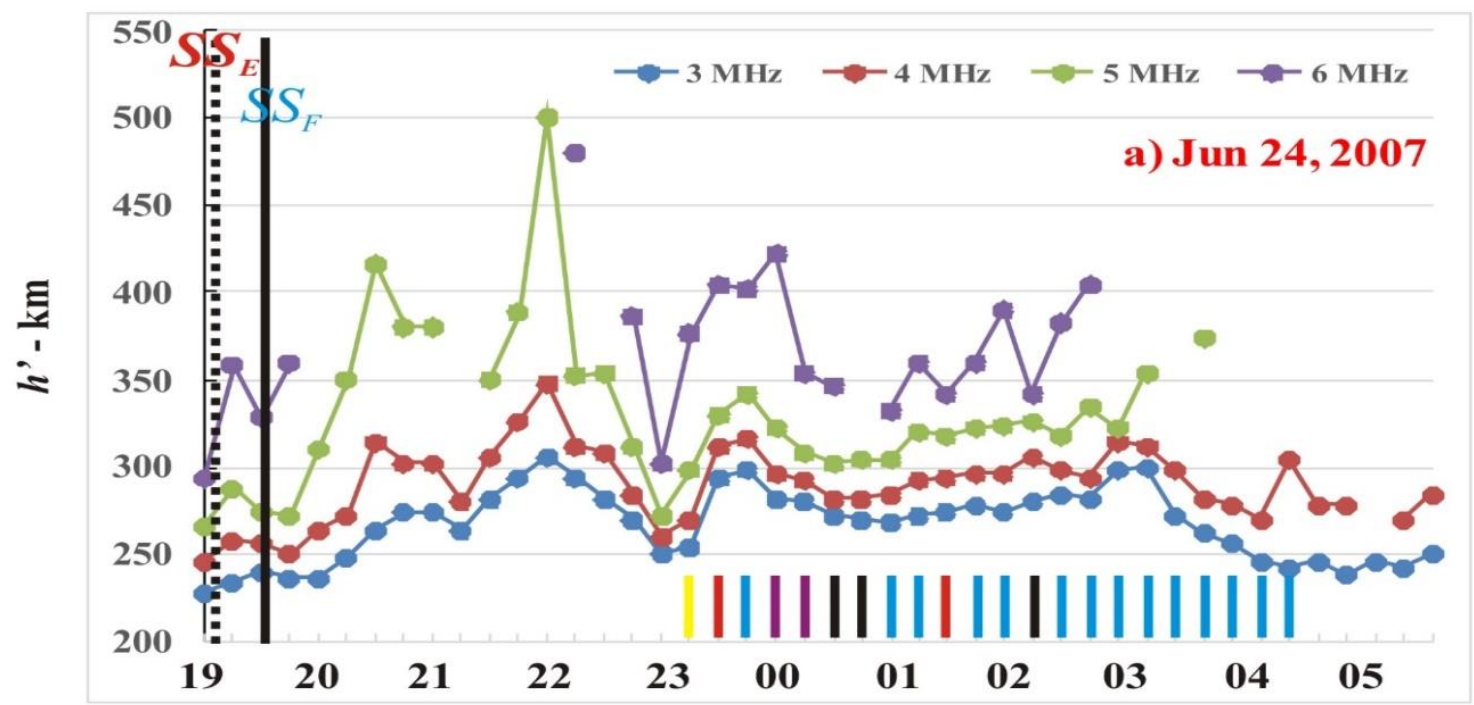

LT - hour

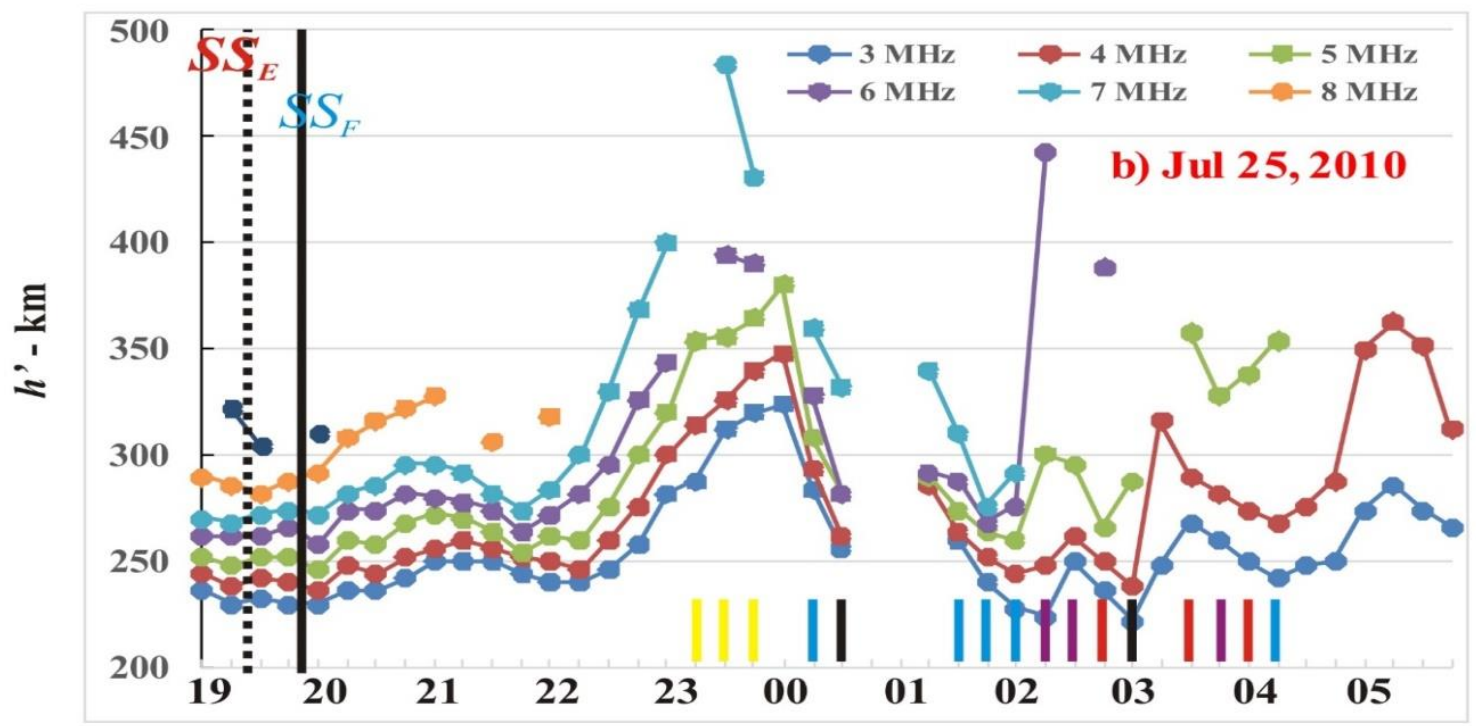

LT - hour

Fig. 5. Nighttime ionospheric behaviors in Phu Thuy: (a) on 24 June 2007 and (b) on 25 July 2010. Short vertical bars: satellite trace (ST) - yellow, range SF - red, mixed SF - purple, frequency SF - blue, other type (EPB signature) - black

On 24 June 2007, we see the ionosphere is quite low around sunsets. There is an uplifting around 2000 LT followed by a wave-like undulation lasted for about 3 hours. At 2300 LT the ionosphere came down to about $250 \mathrm{~km}$ and ST appeared $15 \mathrm{~min}$ after that. Peak velocity of 
uplifting was around $2330 \mathrm{LT}$ at $44 \mathrm{~m} / \mathrm{s}$ - very high value. SF event occurred continuously for more than 5 hours, started by frequency type and ended by range type. Majority of SF was in range form, as stated by Whalen et al. (1996). During the lifetime of SF, the ionosphere was above $250 \mathrm{~km}$, except the last three SF events when the ionosphere came down to lower than $250 \mathrm{~km}$. We do not know what caused the strong uplifting in the beginning of SF chain while height of ionosphere from $2330 \mathrm{LT}$ to $0345 \mathrm{LT}$ can be related to EBPs' arrival. We suggest that, with two times appearance of EBP signature type, there were three branches of bubbles passing over Phu Thuy during lifetime of this event. This seems to be reasonable when the frequency type occurred right after ST inferred that bubbles moved from the West of Phu Thuy. Examining ionograms at Bac Lieu (1.60 dip latitude), we found that ST first appeared at $2145 \mathrm{LT}$, followed mostly by weak range SF started from $2230 \mathrm{LT}$. The SFs lasted for 5 hours 15 min continuously. To the West of Phu Thuy (no data at Chiang Mai), ionograms at Chumphon (30 dip latitude) showed weak STs at 2330 LT and then SFs occurred from 0015 LT to 0230 LT. All SFs were range type. Keeping in mind that Chumphon is about $600 \mathrm{~km}$ apart in longitude to Bac Lieu (Phu Thuy) so that EBPs may take nearly 2 hours to reach Bac Lieu from Chumphon. If EBPs formed over Bac Lieu at a certain time, they could not be seen by ionosonde at Phu Thuy after 2 hours when they might reach to altitude of about $760 \mathrm{~km}$. And hence, the scene perhaps was EPBs formed and developed right to the East of Chumphon and reached Bac Lieu earlier than Phu Thuy and could be seen both by ionosondes there. Figure 10 in Tsunoda (2015) paper explained why Chumphon did not get echoes reflected back if signals went through the bubbles. After that, second EBP cluster, perhaps formed from West of Chumphon, reached Chumphon and than kept reaching Bac Lieu and Phu Thuy so that EF events there lasted for more than 5 hours. There seems to be a relationship between these two clusters and branches as inferred from signatures seen at Phu Thuy as mentioned above.

On 25 July 2010, likes on 24 June 2007, the bottomside of the F layer was quite low around sunsets. Wave - like modulation started just after
F-region sunset with very high uplifting occurred around $2215 \mathrm{LT}$ and peak of velocity reached around 23:00 LT at $26.7 \mathrm{~m} / \mathrm{s}$. Sporadic E occurred during 0045 LT - 0115 LT so that we do not know behaviors of $\mathrm{F}$ layer around this time. Clear $\mathrm{F}$ traces occurred two times, at $0000 \mathrm{LT}$ and 0315 LT in between the SF events. Unlike 24 June 2007 , about half of SF appeared when height of the ionosphere was above $250 \mathrm{~km}$ and less than half of $\mathrm{SF}$ is in form of range type. We saw more frequency and mixed types on this night. We saw EPB signature occurred twice around the time of clear F traces. On this night, SF chain started and ended both by range type. Especially, we saw STs three time, moving downward, in the beginning of SF chain. We again think about two branches of EPBs indicated by two signatures as shown here. Total lifetime of this night event is more than 4 hours. Employing ionograms at Bac Lieu, we found 25 July 2010 was very quiet there, and the same as Chiang Mai station $\left(11.8^{0}\right.$ dip latitude, about $700 \mathrm{~km}$ West of Bac Lieu). We again suggest that, since the fact that the ionosphere over Chiang Mai was quiet, EPBs might form from East of Chiang Mai so that they could not be seen from Chiang Mai. Next step is eastward movement to reach Phu Thuy. But, unlikely the 24 June 2007 case, EBPs could not be seen by ionosonde at Bac Lieu because the bottomside of $F$ layer here might be smoothened out by chemical processes as the layer moved downward (see Figure 8 in Tsunoda 2015). This scene perhaps is in good agreement with the fact that we saw clear $F$ traces, EBP signature and some frequency type which indicate fully developed EBPs occurrence and movement.

We found, by these two case studies, no evidence of a sequence of SF occurrence like range - mixed - frequency types as seen at equatorial stations and sometimes at Phu Thuy. We notice that all examples mentioned in these papers (and references therein) are for high solar condition period. This sequence is quite well understood by using Tsunoda's hypothesis of upwellings. In there, range type appeared in the earlier phase caused by oblique echoes from bottomside upwellings. Mixed type is a combination of both range spreading at lower frequencies and frequency spreading at higher frequencies caused by signals coming into the bubble (see Fig 8 in 
N.T. Trang, et al./Vietnam Journal of Earth Sciences 37 (2015)

Tsunoda 2015). Finally, frequency type occurred when bottomside undulations are flattened out when the ionosphere moves. All this happens because of the geometry of the geomagnetic field lines over the dip equator - they are horizontal parallel to the ground so that the echoes reach offplane will not come back to the ionosonde. Coming away from the dip equator, this geometry changes so that most of SF events are combined echoes results from the directions as explained above.

Finally, we notice that although almost EBP events in June solstice during low to moderate solar condition period are evolving type, compared to the other one - drifting type (Ajith K. K., 2015), we found most two interesting case studies in this paper drifting type with seeding area maybe close to the stations.

\section{Conclusions}

Climatology of SF in years of low solar conditions observed at Phu Thuy shows peak in post-midnight in local time and around June solstice. These are in good agreement with global satellite measurements and ionosonde results in Baguio under the same conditions. This is to show strong evidence of good correlation between SF at Phu Thuy and EBPs over dip equator. Using case studies, we then found that range type SF at nonequator stations is results from complex oblique reflections from bubble structures in the vicinity. Compared to typical types of SF for aquaria stations, we suggest the new type namely EBP signature as indicator of EBP occurrence. More detailed geometries are need to understand under which conditions that different type of SF at offequator stations can be formed.

\section{Acknowledgements}

One of the authors (NTT) was supported by "Assistance program for young researchers" of Vietnam Academy of Science and Technology in 2014. We would like to thank Dr. Tatsuhiro Yokoyama - PI of SEALION (NICT) for kind support with permission of using ionograms.

\section{References}

Abdu M.A., R.T. de Medeiros, J.A. Bittencourt and I.S. Batista, 1983, Vertical ionization drift velocities and range type spread $F$ in the evening equatorial ionosphere, J. Geophys. Res. 88 (399).

Abdu M.A., J. H. A. Sobral, O. R. Nelson and I.S. Batista, 1985: Solar cycle related range type spread-F occurrence characteristics over equatorial and low latitude stations in Brazil, J. Atmos. Solar-Terr. Phys., 47 (8-10), p.901 - 905.

Ajith K. K., S.TulasiRam, M.Yamamoto, T.Yokoyama, V. Sai Gowtam, Y. Otsuka, T. Tsugawa, and K. Niranjan, 2015: Explicit characteristics of evolutionary-type plasma bubbles observed from Equatorial Atmosphere Radar during the low to moderate solar activity years 2010-2012, J. Geophys. Res. Space Physics, 120, doi:10.1002/2014JA020878.

Basu B., 1997: Generalized Rayleigh-Taylor instability in the presence of time-dependent equilibrium, J. Geophys. Res., 102 (A8)

Batista I. S., Abdu M. A. and A. J. Bittencourt, 1986: Equatorial $\mathrm{F}$ region vertical plasma drift: seasonal and longitudinal asymmetries in the American sector, J. Geophys. Res., 91 (A11).

Burke W. J., G. S. Sagalyn Rastogi, M. Ahmed, F. G. Rich, D. E. Donatelli, P. J. L. Wildman, 1979: Postsunset refilling of the low-latitude topside ionosphere, J. Geophys. Res., 84 (A8).

Chandra H., Rastogi R.G., 1972: Spread F at magnetic equatorial station Thumba, Annales Geophysicae, 28 (1), $37-44$.

Dao, E., M. C. Kelley, P. Roddy, J. Retterer, J. O. Ballenthin, O. de La Beaujardiere, and Y.-J. Su, 2011: Longitudinal and seasonal dependence of nighttime equatorial plasma density irregularities during solar minimum detected on the C/NOFS satellite, Geophys. Res. Lett., 38, L10104, doi:10.1029/2011GL047046.

Gentile L.C., W.J. Burke, and F.J. Rich, 2006: A climatology of equatorial plasma bubbles from DMSP 1988 - 2004, Radio Sci., 41 (RS5S21).

Gentile, L. C., W. J. Burke, P. A. Roddy, J. M. Retterer, and R. T. Tsunoda, 2011: Climatology of plasma density depletions observed by DMSP in the dawn sector, J. Geophys. Res., 116, A03321, doi:10.1029/2010JA016176.

Hoàng Thái Lan, Nguyễn Thu Trang, John MacDougall, 2011: The occurrence of equatorial spread $\mathrm{F}$ over Ho Chi Minh City in years 2003 and 2005, Vietnam Journal of Earth Sciences, Vol 33 (No. 2), doi: 10.15625/jse.v33i2.287. 
Vietnam Journal of Earth Sciences 37 (2015) 307-317

Marasigan V. S. J., 1960: Spread $F$ in Baguio through haft of a solar cycle, Journal of Atmospheric and Terrestrial Physics, $18,43-47$.

Mendillo M. and Baumgardner Jeffrey, 1982: Airglow characteristics of Equatorial Plasma Depletions, J. Geophys. Res. 87 (A9), pp.7641-7652.

Lyon A. J., Skinner N. J., Wright R. W., 1961: Equatorial spread F at Ibadan - Nigeria, Journal of Atmospheric and Terrestrial Physics, 21, 100-119.

Rastogi R.G., Vyas G.D., 1977: Range and frequency spread F at Huancayo, Indian Academy of Sciences. Proceeding, 86A (4), 417 - 421.

Sales G. S., B. W. Reinisch, J. L. Scaili, C. Dozois, 1996: Spread F and structure of ionization depletions in the southern anomaly region, J. Geophys. Res. 101 (A12), 26819 - 26827.

Thampi S.V., R. Tsunoda, L. Jose and T.K. Pant, 2012: Ionogram signatures of large-scale wave structure and their relation to equatorial spread F, J. Geophys. Res. 117 (A08314).

Trần Thị Lan and Đào Thế Cường, 2013: Some characteristic of equatorial spread $\mathrm{F}$ at Phu Thuy over a solar cycle, Vietnam Journal of Earth Sciences, Vol 35 (No. 3).

Tsunoda R.T., S.V. Thampi, T.T. Nguyen and M. Yamamoto, 2013: On validating the relationship of ionogram signatures to large-scale wave structure, J. Atmos. Solar-Terr. Phys. 103 (30), pp. 30-35.

Tsunoda R. T., 2015: Upwelling: a unit of disturbance in equatorial Spread F, Progress in Earth and Planetary Science (2015) 2:9, doi 10.1186/s40645-015-0038-5.
Tsunoda R. T., 1981: Time evolution and dynamics of equatorial backscatter plumes: 1. Growth phase, J. Geophys. Res. 86 (A1)

Weber E. J., Buchau J., Eather R. H., Mende S. B., 1978: North-South Aligned Equatorial Airglow Depletions, J. Geophys. Res. 83 (A2).

Weber E. J., S. Basu,T. W. Bullett, C. Valladares, G. Bishop, K. Groves, H. Kuenzler, P. Ning, P. J. Sultan, R. E. Sheehan and J. Araya, 1996: Equatorial plasma depletion precursor signatures and onset observed at 110 south of the magnetic equator, J. Geophys. Res. 101 (A12).

Whalen J. A., 1996: Mapping a bubble at dip equator and anomaly with oblique ionospheric soundings of range spread F, J. Geophys. Res. 101 (A3).

Whalen J. A., 1997: Equatorial bubbles observed at the north and south anomaly crests: Dependence on season, local time and dip latitude, Radio Science, 32 (No. 4).

World Data Center A for Solar - Terrestrial Physics, 1978: U.R.S.I Handbook of ionogram interpretation and reduction.

Zalesak S. T., Ossakow S. L., Chaturvedi P. K., 1982: Nonlinear Equatorial Spread F: The Effect of Neutral Winds and Background Pedersen Conductivity, J. Geophys. Res. 87 (A1)

http://seg-web.nict.go.jp/sealion/ALLFC/ionogram/index.html. www.sidc.oma.be (WDC-SILSO, Royal Observatory of Belgium, Brussels).

http://wdc.kugi.kyoto-u.ac.jp/wdc/Sec3.html. 